\title{
Predictability of the Theory of Planned Behavior Constructs in Practice of Physical Activity of Recuperating Alcoholics
}

\author{
Lucy Amanya Mutuli (PhD) ${ }^{*}$, Peter Bukhala (PhD), Gordon Nguka (PhD) \\ Masinde Muliro University of Science and Technology 190-50100 \\ *Corresponding Author: Lucy Amanya Mutuli (PhD), Masinde Muliro University of Science and \\ Technology 190-50100
}

\begin{abstract}
:
Background: Recuperating alcoholics in general population do not follow moderate-vigorous physical activity which hinders effective rehabilitation, increases relapse and risks to metabolic conditions. Therefore comprehension of factors associated with practice of physical activity allows health professionals plan appropriate interventions during rehabilitation to improve physical activity initiation and intensity.
\end{abstract}

Objective: We aimed at determining predictive power of psychosocial factors influencing practice of physical activity during rehabilitation.

Methods: This cross-sectional study was conducted from August to November 2018 amongst recuperating alcoholics receiving rehabilitation in Asumbi treatment center of Homabay County, Kenya. Asumbi rehabilitation center was purposively sampled and 207 respondents were stratified into 129 males and 78 females. Structural equation modeling determined predictive power of latent variables.

Results: The model fitted data acceptably well, $\chi^{2}=200, P<.001, \quad R M S E A=.087, \quad C F I=0.91$, $C M I N / D F=2.22, T L I=0.89$ and Hoelter's critical $N=200$ with regard to physical activity. Regression weights showed predictive power for alcoholic's attitude $(\beta=0.62, p<0.01)$ subjective norm $(\beta=0.60, p<0.01)$ perceived behavioral control $(\beta=0.55, p<0.01 ; \beta=0.09, p>0.05)$.

Conclusion: This study has recognized attitude, subjective norm and perceived behavioral control as motivational components of practicing physical activity that should be focused on when designing programs to uphold these practice during alcohol rehabilitation. The study has established cognitive aspects that manipulate recuperating alcoholic's practice of physical activity which has essential implication to health professionals, relevant stakeholders, policy makers and researchers in Kenya who are directly or indirectly involved in activities of alcohol rehabilitation.

\section{INTRODUCTION}

Alcoholic's attitude has been reported to be a crucial motivational factor in promoting practice of physical activity during alcohol rehabilitation; however, evidence suggests this is not basically the case (Friederichs et al., 2015). For recuperating alcoholics to be inspired to practice physical activity, subjective norm and perceived behavioral control are predictors of physical activity during alcohol rehabilitation (Martinsen, 2008). Physical activity intention is a significant predictor of practicing physical activity during alcohol rehabilitation. Studies have described many factors associated with the intention to be physically active during alcohol rehabilitation (Martinsen, 2008; Chepkwony, Chelule \& Barmao, 2013; Barry, 2017). These factors have been identified at the individual and the societal levels, which affect the magnitude and patterns of consumption and can increase the risk of alcohol use disorders and other alcohol-related problems in drinkers and others (Greenwood et al., 2011; Chaput et al., 2011). Environmental factors such as availability of alcohol and effectiveness of alcohol policies are relevant factors in explaining alcohol consumption and alcohol-related harm (Stubbs et al., 2014; Petter et al., 2009). Understanding factors associated with intention to practice physical activity allows health professionals plan and evaluate appropriate interventions to improve physical activity initiation and intensity. Public health guidelines promote at least $150 \mathrm{~min} / \mathrm{week}$ of moderate-vigorous leisure-time physical activity to aim at decreasing the risks for metabolic diseases for alcoholics (Reads et al., 2001). However, the majority of recuperating alcoholics in the general population do not follow this prescription for enough moderate-vigorous exercise and this may be 
contributing to the rising numbers of alcoholics being affected by obesity, high blood pressure and diabetes type (Stubbs et al., 2014). Evidence for the benefit of physical activity comes from studies showing that alcoholic individuals who maintain a physically active lifestyle promotes effective rehabilitation and are less likely to relapse (Naci \& Ioannidis, 2013; Park et al., 2011). Physical activity variability is significantly influenced by alcoholic's attitude, social pressures, and control factors. Alcoholic's appreciation of physical activity and its' perceived benefits are the factors that increase favorable attitude towards physical activity intention. Previous studies have also supported alcoholic's attitude to be a significant predictor of physical activity intention (Herbsleb et al., 2013; Karoly et al., 2013; Lisha et al., 2013). However, alcoholic's attitude independently cannot influence physical activity without the social support of the people significant to the alcoholic. As a health behavior, physical activity decision is therefore guided not only by alcoholic's own underlying attitudes, knowledge and beliefs but also by the perception of what other people think. Cognitive models provide a useful framework for studying alcoholic's social norms, attitude and beliefs that constitute factors in relation to physical activity and some studies have applied the Theory of Planned Behavior (TPB) to physical activity (Greenwood et al., 2011). To date little is known on the way these factors can be perceived, measured and applied to promote physical activity amongst alcoholics in Kenya, since most studies have been done on alcoholics in the developed countries. The aim of this study was to assess the predictive power of psychosocial factors that include alcoholic's attitude, subjective norm and perceived behavioral control on practice of physical activity of alcoholics' under rehabilitation in Asumbi rehabilitation center of Homabay County.

\section{MeThodS AND DATA}

\subsection{Study Framework}

The study adapted Ajzen's TPB model (Figure 1) to fit factors that influence practice of physical activity of recuperating alcoholics. The TPB model works on the basis that the approach to target practice is to assess behavioral intention, which in turn is seen to be an operation of 4 exogenous variables: attitudes, subjective norm, perceived control, and intention. In this context, alcoholic's attitude was the certainty about likely outcomes of practice of physical activity multiplied by evaluation of these outcomes (behavioral beliefs). Subjective norm was the belief of the recuperating alcoholics over important people in their life that may or may not have influenced practice of physical activity multiplied by the level of compliance to such influences (normative beliefs). Perceived behavioral control was viewed as control factors to promote or inhibit the recuperating alcoholic to practice physical activity multiplied by the power they had over those factors (control beliefs). Perceived behavioral control was measured both directly and indirectly since physical activity is not under completely volitional control. Therefore, attitude and subjective norm were posited to have influenced physical activity indirectly through recuperating alcoholic's intention. While perceived behavioral control both indirectly and directly manipulated physical activity. When a variable is believed to "cause" another variable, the relationship between the variables is shown as a directed arrow, from cause to effect. Covariation between 2 variables is shown as a 2-headed arrow connecting the variables. As a theory of competency and mastery, factors influencing practice of physical activity describe that initiation and persistence toward the behavior are determined primarily by recuperating alcoholic's cognitive judgments and expectations. To comprehend practice of physical activity using the TPB model, an elicitation study was initially conducted prior to the current study to elicit salient beliefs on which exogenous variables are based. This was then employed to construct a questionnaire, which was pretested and used to assess the influence of these factors on practice of physical activity (see Figure 1). Three research questions were examined:

1. What is the predictive power of recuperating alcoholics' attitude on practice of physical activity?

2. What is the predictive power of recuperating alcoholics' subjective norm on practice of physical activity?

3. What is the predictive power of recuperating alcoholics' perceived behavioral control on practice of physical activity? 


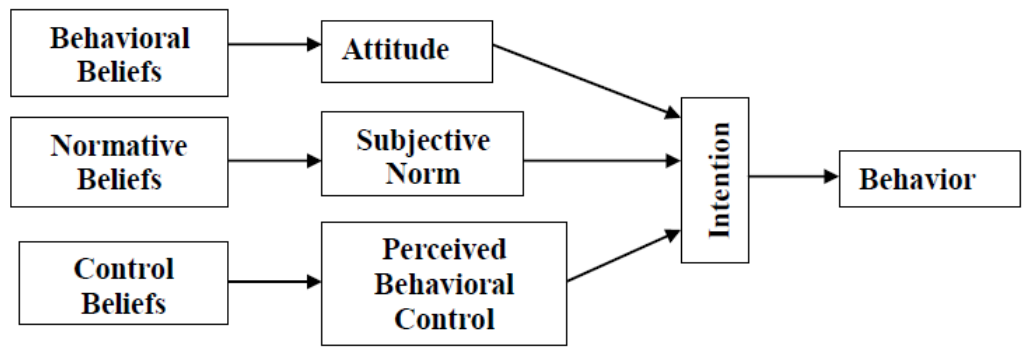

Figure1. Theory of Planned Behavior (Ajzen, 1991)

\subsection{Study Area and Design}

Asumbi-Homabay located in Homabay County, Nyanza region of Kenya formed the study area mainly because of the existence of Asumbi rehabilitation center. This center was purposively sampled with the target that it receives numerous alcoholic patients both males and females from different parts of the country, offers standardized rehabilitation services to alcoholic rehabilitees and it's accredited by NACADA. This cross-sectional study was conducted from August to November 2018 amongst recuperating alcoholics receiving rehabilitation in Asumbi treatment center of Homabay County, Kenya. Permission was obtained from the School of Graduate Studies. Ethical approval was given by National Council for Science and Technology. Research authorization was granted by the Ministry of Public Health of Homabay County. We sought informed consent from the respondents who were informed on the research procedures, details, and assured of confidentiality. Enrolled recuperating alcoholics received a preliminary medical examination, detoxification and further medical and psychological assessment, before the rehabilitation programme was started.

\subsection{Sampling Techniques and Criteria}

Purposive sampling technique was used to select Asumbi rehabilitation center as the study site because it's the only rehabilitation center that admits and rehabilitates exclusively alcoholics. Stratified sampling was used to select 207 respondents from each stratum (males and females). A sample of 129 respondents from the male stratum and 78 respondents from the female stratum was developed $\left(\frac{230}{368} \times 207=129 \frac{138}{368} \times 207=78\right)$.

\section{Inclusion Criteria Included:}

1. Female and male alcoholics aged $15-65$ years who were admitted not more than a week prior to start of the study and those who voluntarily consented to participate in the study.

2. Alcoholics exclusively suffering from alcoholism and not other addictive substances

\section{Exclusion Criteria Included:}

1. Alcoholics with active psychotic symptoms were excluded.

2. Alcoholics not intending to complete the three months of rehabilitation in Asumbi center were not inclusive.

\subsection{Data Collection Instrument and Procedure}

A questionnaire was divided into sections each measuring the influence of attitude, subjective norm and perceived behavioral control of the alcoholic on practice of physical activity. A seven point Likert scale was constructed along a continuum range from totally disagree/not all/extremely unlikely $=1$; moderately disagree/not all/extremely unlikely $=2$; slightly disagree/not all/extremely unlikely $=3$; undecided $=4$; slightly agree/very much/extremely likely $=5$; moderately agree/ very much /extremely likely $=6$; to totally agree/ very much /extremely likely $=7$ was used to measure all the variables. Higher scores indicated more positive attitude towards practice of physical activity in alcohol rehabilitation. A 7-point scale, with end points of (7) and (1) was used to elicit the alcoholic's beliefs about significant referents' expectations on practice of physical activity during alcohol rehabilitation. Another set of 7-point scales evaluated alcoholic's motivation to comply with significant others' expectations and was contained in end points (1) not at all and (7) very much. The subjective norm score was derived from multiplying each expectation by the corresponding compliance item and 
summing the product; a higher score indicated greater perceived social pressure to practise of physical activity in alcohol rehabilitation. Perceived physical activity control was also measured according to Ajzen's guidelines (1988). Three items with 7-point response scales elicited the alcoholics' perceptions on physical activity in alcohol rehabilitation. The anchors were extremely likely (7) to extremely unlikely (1). One additional item measured perceptions of confidence in ability on a 7-point scale, ranging from strongly disagree (1) strongly agree (7). Scores were summed and divided by the number of items for a possible mean score of 1 to 6.5; higher scores reflected greater perceived control. Physical activity intentions were measured with one 7-point scale, containing end points of strongly disagree (1) and strongly agree (7). The midpoint of the scale represented unsure practice of physical activity during alcohol rehabilitation. To establish validity, the questionnaire was given to two experts to evaluate the relevance of each item in the instrument to the objectives (content validity). The experts appraised what appeared to be valid for the content, the test attempted to measure (face validity). The degree to which a test measured a sufficient sample of total content that was purported to measure was considered (sampling validity). The questionnaire was administered on respondents and the interview responses filled in by the researcher to gather information on the influence of attitude, subjective norm and perceived behavioral on practice of physical activity during alcohol rehabilitation. The respondents were then interviewed through previous booked appointments and each interview lasted for a maximum of 1 hour.

\subsection{Data Analysis}

Data was entered into SPSS version 15 to calculate reliability tests where Cronbach's alpha was used to assess the consistency of the questions. Structural Equation Modelling using AMOS version 7 was used to determine the influence of attitude, subjective norm and perceived behavioural control on practice of physical activity during the rehabilitation of alcoholics. The overall model fit was evaluated using chi-square (CMIN) and relative chi-square divided by degrees of freedom (CMIN/df), comparative fit index (CFI), the standardized root-mean-square error of approximation (RMSEA), Hoelter's critical N, and Bollestine bootstrap. Comparative fit index (CFI) and Tucker Lewis index (TLI), values greater than 0.90 were considered satisfactory (Garson, 2009). RMSEA less than 0.08 was also considered satisfactory (Schumacker \& Lomax, 2004). CMIN/df was considered fit when it ranged between 3:1 and was considered more better when closer but not less than 1(Kline, 1998). Hoelter's critical $\mathrm{N}$ for significance level of .05 and .01 was used where bootstrap samples was set at 200 (Hoelter, 1983).

\section{RESUltS}

Predictive power of a theory refers to its ability to generate testable forecasts. A theory with strong predictive power is highly valued, because the forecasts can often support the validity of the theory. The concept of predictive power involves a known phenomenon that is retrospectively explained by a given theory which allows a prospective test of theoretical understanding. In this study, the predictive power of alcoholic's attitude, subjective norm and perceived behavioral control in extrapolating physical activity was tested through physical activity intention and explained the total variance of these predictors (figure 2).

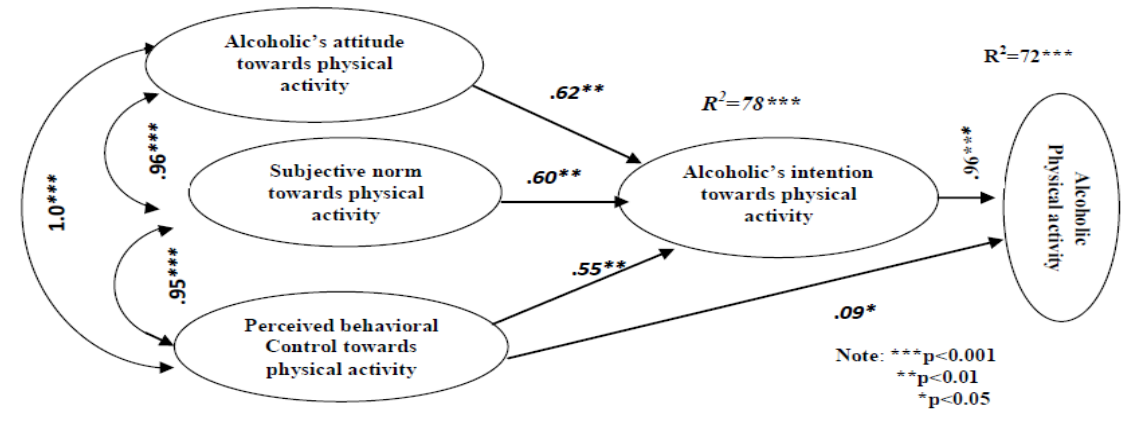

Figure2. Default Model of physical activity

\section{Research Question 1: Predictive Power of Alcoholic's Attitude on practice of Physical Activity}

The predictive power of alcoholic's attitude on physical activity intention was given by: 
Physical Activity Intention $=0.62$ attitude + residuals

$\mathrm{Y}=0.62 \mathrm{X}+\mathrm{e}$

Where: $\mathrm{Y}=$ Intention, $\mathrm{X}=$ Attitude, $\mathrm{e}=$ Residual

This finding indicated that a unit change in alcoholic attitude was associated with a change of 0.62 units in physical activity intention.

\section{Research Question 2: Predictive Power of Alcoholic's Subjective Norm on practice of Physical Activity}

The predictive power of subjective norm on physical activity intention was given by:

Physical Activity Intention $=0.60$ subjective norm+ residuals

$\mathrm{Y}=0.60 \mathrm{X}+\mathrm{e}$

Where: $\mathrm{Y}=$ Intention, $\mathrm{X}=$ Subjective norm, $\mathrm{e}=$ Residual

This finding indicated that a unit change in subjective norm was associated with a change of 0.60 units in physical activity intention.

\section{Research Question 3: Predictive Power of Perceived Behavioral Control on practice of Physical Activity}

The predictive power of perceived behavioral control on physical activity intention was given by:

Physical Activity Intention $=0.55$ perceived behavioral control + residuals

$\mathrm{Y}=0.55 \mathrm{X}+\mathrm{e}$

Where: $\mathrm{Y}=$ Intention, $\mathrm{X}=$ Perceived Behavioral Control, $\mathrm{e}=$ Residual

This finding indicated that a unit change in perceived behavioral control was associated with a change of 0.55 units in physical activity intention.

\subsection{Fit Indices of Default Model}

As shown in (Table, 1) the default model's chi-square value was not significant at 0.05 significance level $\left(\chi^{2}=200, \mathrm{df}=90, \mathrm{p}=0.12, \chi^{2} / \mathrm{df}=2.22\right)$ and all other indices indicated that the default model was acceptable (RMSEA=.087, CFI=0.91, CMIN/DF=2.22, TLI=0.89) and Hoelter's critical N=200.

Table1. Fit Indices of Default Model

\begin{tabular}{|l|l|l|}
\hline Fit Indices & Recommended fit Measures & Default Measures \\
\hline RMSEA & 0.09 or less is better & 0.087 \\
\hline CFI & above 0.9 is good fit & 0.91 \\
\hline CMIN/DF & between 2-3 & 2.44 \\
\hline TLI & $>0.8$ is good fit & 0.89 \\
\hline Hoelter's Critical N & $>200$ adequate & 207 \\
\hline p & $>0.10$ good fit & 0.12 \\
\hline
\end{tabular}

Note: RMSEA=Root mean square residual; $\mathrm{CFI}=$ Comparative fit index; $\mathrm{CMIN} / \mathrm{DF}=\mathrm{Chi}$-square/degree of freedom; TLI $=$ Tucker-Lewis Index; $\chi^{2}=$ Chi-square

\subsection{Discussion}

Respondents' attitude statistically influenced practice of physical activity $(\beta=0.62, p<0.01, n=207)$, it was a significant predictor of physical activity as compared to subjective norm $(\beta=0.60, p<0.01$, $\mathrm{n}=207)$ and perceived behavioral control $(\beta=0.55, \mathrm{p}<0.01, \mathrm{n}=207 ; \beta=0.09, \mathrm{p}>0.05, \mathrm{n}=207)$. This suggested that respondents beliefs about the consequences and corresponding negative or positive judgments about each of these features in practice of physical activity was significant aspect of motivating the respondent to be engaged in physical activity during rehabilitation. The higher the value an individual places on the outcome of performing a behavior, the stronger the positive attitude and the more likely a behavior would be carried out (Chepkwony, Chelule \& Barmao, 2013). According to Barry (2017) attitude was the most important component contributing to intention to 
perform physical activity as they perceived it was important if they wanted to be healthier. Chaput et al., (2011) suggests that attitude was a key component influencing physical activity however; specific factors differ between populations and areas. Thus, participants with more positive attitudes towards physical activity were more likely to report intention to physical activity than those participants with less positive attitudes towards physical activity. Subjective norms have two subcomponents, which include normative beliefs (beliefs about the assumptions that other people or someone important make about certain behavior) and motivation to comply (positive or negative judgments about each belief). When an individual thinks that significant others approve of a behavior and that individual feels it is important to act in line with beliefs of others, a positive subjective norm develops. The stronger the subjective norm, the more likely an individual is going to perform a behavior (Martinsen, 2008). This study reported a subjective norm of $(\beta=0.60, \mathrm{p}<0.01, \mathrm{n}=207)$ in predicting physical activity intention which was the second significant predictor after attitude. Similarly, Sari et al., (2013) reported that encouragement of the family was a specific factor in the subjective norm (standardized coefficients $=0.43$ ) component that influenced older women to perform the exercise. Perceived behavioral control is a reflection of an individual's ability in addition to his or her intention to perform a behavior (Herbsleb et al., 2013). It is largely based on Bandura's self-efficacy, which "refers to beliefs in one's capabilities to organize and execute courses of action required to produce given attainments" (Gossip et al., 2007). Thus in the setting of constraints to perform a behavior, individuals with intentions and higher levels of perceived control would more likely to perform the behavior than individuals with lower levels of perceived control (Greenwood et al., 2011). This study reported perceived behavioral control as a significant third predictor of physical activity intention and was measured directly $(\beta=0.55, \mathrm{p}<0.01, \mathrm{n}=207)$ and indirectly $(\beta=0.09, \mathrm{p}>0.05, \mathrm{n}=207)$. Supporting the current findings French, Popovici \& Maclean (2009) argued that women's household chaos was found to be a major obstacle within the perceived behavioral controls that restricted the practice of physical activity in women. These internal and external factors might be the possible explanation of why men are less active than women, although they were willing to be physically active. In this study it was the not strongest but had a significant predictive factor. The conceptualization and measurement of perceived behavioral control in terms of confidence, and perceived ease or difficulty of practicing physical activity may contribute to the difference in findings between indirect and direct perceived behavioral control. An establishment of a supportive environment may improve a recuperating alcoholic's confidence to overcome physical activity inhibitors.

\section{CONCLUSION}

This study has recognized attitude, subjective norm and perceived behavioral control as motivational components of practicing physical activity that should be focused on when designing programs to uphold these practice during alcohol rehabilitation. The study has established cognitive aspects that manipulate recuperating alcoholic's practice of physical activity which has essential implication to health professionals, relevant stakeholders, policy makers and researchers in Kenya who are directly or indirectly involved in activities of alcohol rehabilitation.

\section{Competing Interests}

The authors declare that no conflict of interests exists.

\section{Authors' Contributions}

All authors were involved with the drafting of the research paper, critically reviewed the manuscript and approved the final version submitted for publication.

\section{ACKNOWLEDGMENTS}

The authors sincerely thank participants who shared their experiences, and contributed needed information to the study. All those contributed to the success of this study in one way or another are also recognized.

\section{REFERENCES}

[1] Ajzen, I. (1988). Attitudes, Personality and Behavior. Milton-Keynes: Open University Press. Erlbaum, Mahwah, NJ, pp. 173-221. 
[2] Ajzen, I. (1991). The Theory of Planned Behavior, Organizational Behavior and Human Decision Process. Journal of Applied Social Psychology, 50: $109-119$

[3] Chaput, J. P, Klingenberg, L, Rosenkilde, M, \& et al. (2011). Physical Activity Plays an Important Role in Body Weight Regulation. Journal of Obesity. 10.1155/2011/360257.

[4] Chepkwony, S. J. Chelule, E. \& Barmao, A.C (2013). An Investigation into Prevalence \& Factors Contributing to Relapse Among Alcoholics In Selected Rehabilitation Centers in Nairobi County, Kenya. International Journal of Innovative Research \& Development. 2(8)

[5] Barry, A.E. (2017). Using Theory-based constructs to explore the impact of Greek membership on Alcohol-related Beliefs and Behaviors: A Systematic Literature Review. Journal of American College Health, 56(3): 307-315

[6] Hoelter, J. W. (1983). The Analysis of Covariance Structures: Goodness-of-fit Indices. Sociological Methods and Research, 11: 325-344.

[7] Martinsen, E. W, (2008). Physical Activity in the Prevention and Treatment of Anxiety and Depression. Nordic Journal of Psychiatry, 62(47)25-29.

[8] Sari. S, Bilberg. R, Kurt J, Søgaard-Nielsen, A, Nielsen. B \& Roessle, K.K (2013). Physical Exercise as a Supplement to Outpatient Treatment of Alcohol use Disorders a Randomized Controlled Trial. BMC Psychology, 1:23

[9] Schumacker, R.E, \& Lomax. G, R. (2004). A Beginner's Guide to Structural Equation Modeling, Lawrence Erlbaum Associates, ISBN 0805840184, 978060584086

[10] Kline, R. B. (1998). Principles and Practice of Structural Equation Modeling. New York

[11] Garson, G. D. (2009). Structural equation modeling (Retrieved on 2009-12-16): http://faculty.chass_ncass. ncsu.edu /garson/Pa 765/structure.htm

[12] French, M. T., Popovici, I., \& Maclean, J. C. (2009). Do alcohol consumers exercise more? Findings from a national survey. Journal of Infection, 24, 2-10.

[13] Friederichs, L. A., Blow, F. C., Hutchinson, D. \& Barry, K. L. (2015). Health Care utilization by older alcohol-using veterans: Effects of a Brief intervention to reduce at-risk drinking. Health Education and Behavior, 30(3): 305-321.

[14] Gossop, M.,Neto, D., Radovanovic,M., Batra, A., Toteva, S.,Musalek,M., Skutle,A.,\&Goos, C.(2007). Physical health problems among patients seeking treatment for alcohol use disorders: A study in six European cities. Addiction Biology, 12(2), 190-196.

[15] Greenwood, B. N., Foley, T. E., Le, T. V., Strong, P. V., Loughridge, A. B., Day, H. E., \& Fleshner, M. (2011). Long-term voluntary wheel running is rewarding and produces plasticity in the mesolimbic reward pathway. Behavioral Brain Research, 217(2), 354-362.

[16] Herbsleb,M., Schulz, S., Ostermann, S., Donath, L., Eisenträger, D., Puta, C., Voss, A., Gabriel,

[17] H.W., \& Bär, K. J. (2013). The relation of autonomic function to physical fitness in patients suffering from alcohol dependence. Drug and Alcohol Dependence, 132(3), 505-512.

[18] Karoly, H. C., Stevens, C. J., Thayer, R. E., Magnan, R. E., Bryan, A. D., \& Hutchison, K. E. (2013). Aerobic exercise moderates the effect of heavy alcohol consumption on white matter damage. Alcoholism, Clinical and Experimental Research, 37(9), 1508-1515.

[19] Lisha, N. E., Sussman, S., Fapa, F., \& Leventhal, A. M. (2013). Physical activity and alcohol use disorders. American Journal of Drug and Alcohol Abuse, 39(2), 115-120.

[20] Naci, H., \& Ioannidis, J. P. (2013). Comparative effectiveness of exercise and drug interventions on mortality outcomes: Meta-epidemiological study. BMJ, 347, f5577.

[21] National Institute of Clinical Health and Excellence (2011). Alcohol-use disorders: Diagnosis, assessment and management of harmful drinking and alcohol dependence. London: National Institute of Clinical Health and Excellence.

[22] Park, S., Cho, M. J., Cho, S. J., Bae, J. N., Lee, J. Y., Park, J. I., Kim, J. Y., Lee, D.W., \& Hong, J. P. (2011). Relationship between Physical Activity and Mental Health in a nationwide sample of Korean adults. Psychosomatics, 52(1), 65-73.

[23] Petter, M., Blanchard, S., Kemp, K. R., Mazoff, A. S., \& Ferrier, S. N. (2009). Correlates of exercise among coronary heart disease patients: Review, implications and future direction. European Journal of Cardiovascular Prevention and Rehabilitation, 16, 515-526.

[24] Read, J. P., Brown, R.A., Marcus, B.H., Kahler, C.W., Ramsey, S. E.,Dubreuil,M. E., Jakicic, J.M., \& Francione, C. (2001). Exercise attitudes and behaviors among persons in treatment for alcohol use disorders. Journal of Substance Abuse Treatment, 21(4), 199-206. 
Predictability of the Theory of Planned Behavior Constructs in Practice of Physical Activity of Recuperating Alcoholics

[25] Stubbs, B., Eggermont, L., Soundy, A., Probst, M., Vandenbulcke, M., \& Vancampfort, D. (2014). What are the factors associated with physical activity (PA) participation in community dwelling adults with dementia? A systematic review of PA correlates. Archives of Gerontology and Geriatrics, 59(2), 195-220.

Citation: Lucy Amanya Mutuli (PhD), et.al. "Predictability of the Theory of Planned Behavior Constructs in Practice of Physical Activity of Recuperating Alcoholics" International Journal of Sports and Physical Education (IJSPE), vol 6, no. 2, 2020, pp. 1-8. doi: http://dx.doi.org/10.20431/2454-6380.0602001.

Copyright: (C) 2020 Authors. This is an open-access article distributed under the terms of the Creative Commons Attribution License, which permits unrestricted use, distribution, and reproduction in any medium, provided the original author and source are credited. 